\title{
Practice patterns of post-radical prostatectomy incontinence surgery in Ontario
}

\author{
Christopher J.D. Wallis, MD; ${ }^{*}$ Sender Herschorn, MD, FRCSC; ${ }^{*}$ Ying Liu, MD; ; Lesley K. Carr, MD, FRCSC; \\ Ronald T. Kodama, MD; ${ }^{*}$ Laurence H. Klotz, MD, FRCSC,; Refik Saskin, MD; ${ }^{\dagger}$ Robert K. Nam, MD, FRCSC*
}

*Division of Urology, Sunnybrook Health Sciences Centre, University of Toronto, Toronto, ON; 'Institute of Clinical Evaluative Sciences (YL, RS), Sunnybrook Health Sciences Centre, University of Toronto, Toronto, ON

Cite as: Can Urol Assoc J 2014;8(9-10):e670-4. http://dx.doi.org/10.5489/cuaj.1959 Published online October 22, 2014.

\section{Abstract}

Introduction: We assess the practice patterns of artificial urinary sphincter (AUS) and urethral sling insertion after radical prostatectomy (RP) from a large population-based cohort.

Methods: We examined 25346 men in Ontario, Canada who underwent RP between 1993 and 2006. Using hospital and cancer registry data, we identified patients who subsequently underwent an incontinence procedure. We characterized the practice patterns of post-prostatectomy incontinence procedures across Ontario during the study interval.

Results: A total of $703(2.8 \%)$ men underwent subsequent insertion of an AUS and $282(1.1 \%)$ underwent a urethral sling procedure (985 total incontinence procedures, 3.9\%) over the study period. During the study period, 121 hospitals performed RP. Among them, $32(26 \%)$ hospitals performed both RP and AUS/sling procedures, and 89 (74\%) performed RP only. Four hospitals performed AUS/ sling procedures but not RP. Of the 36 institutions that performed AUS/sling procedures, the median annual case volume was 0.29 (interquartile range: $0.083-0.75)$. Of all incontinence procedures, $56 \%$ were performed at 3 academic institutions. When examining observed rates of AUS/sling procedures compared with expected rates from the overall cohort, 15 of 32 hospitals (47\%) performed significantly fewer incontinence procedures than expected given their RP case volume ( $p$ range: $<0.0001-0.0390)$ and $5(16 \%)$ performed significantly more ( $p$ range: $<0.0001-0.038$ ).

Conclusions: A small number of academic institutions provide most of the surgical care for men with incontinence following RP in Ontario. Many centres that perform RP refer out to other centres to surgically manage their patients' incontinence.

\section{Introduction}

Clinically localized prostate cancer is commonly treated with radical prostatectomy (RP). Long-term side effects of RP include urinary incontinence and erectile dysfunction, which may decrease quality of life. ${ }^{1}$ There are many treatment options for urinary incontinence, including lifestyle modifications, biofeedback, medical and surgical therapies. ${ }^{2}$ Surgical options involve either the insertion of an artificial urinary sphincter (AUS) or urethral sling, both of which have been shown to effectively improve urinary continence. ${ }^{3}$

We previously showed that the probability of undergoing surgery to treat incontinence rises with increasing time since the date of RP, reaching $4.8 \%$ at 15 years. ${ }^{4}$ Risk factors included advanced patient age at prostatectomy, radiotherapy after surgery, and surgeon volume.

To date, practice patterns of surgical management of postprostatectomy incontinence have not been assessed at the population level. From this cohort, we examined practice patterns for post-prostatectomy continence procedures in the province of Ontario over a 14-year period.

\section{Methods}

\section{Study population}

The study subjects have previously been described by Nam and colleagues. ${ }^{4}$ Patients were drawn from a retrospective, population-based cohort of men over 18 undergoing a RP for clinically-localized prostate cancer in Ontario from January 1, 1993 to December 31, 2006. These men were identified using a surgical fee code (S651) that is specific to RP from Ontario's single-payer model (Ontario Health Insurance Plan, OHIP). The study protocol was approved by the Sunnybrook Health Sciences Centre research ethics board. 


\section{Outcome measures}

The primary outcome measure was the insertion of an AUS or urethral sling following RP. These were identified using the OHIP fee codes specific to these procedures, S559 and S548, respectively.

\section{Exposure variables}

We collected information as to which specific hospital performed both the RP and AUS or sling procedures. We linked patients from these procedures using the OHIP physician claims-database, the Canadian Institute for Health Information $(\mathrm{ClHI})$ discharge database, and the Ontario Cancer Registry.

\section{Data analysis}

We descriptively characterized the annualized rates of both RP and post-prostatectomy incontinence procedure by hospital site. To evaluate the degree to which post-prostatectomy incontinence was managed at the same institution as the original prostatectomy, we then compared actual and expected frequency of incontinence procedures from each hospital site's RP case volume. To calculate the expected frequency, we used the previously established $4.8 \%$ rate of surgical intervention. We excluded sites that had not

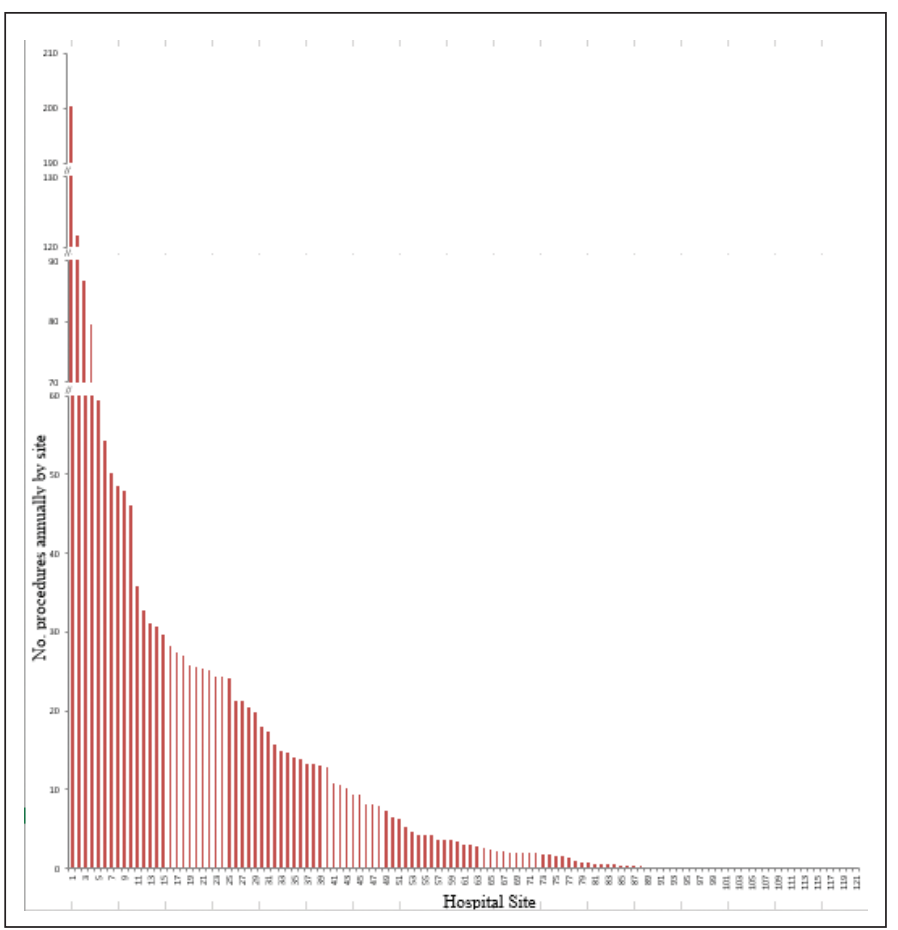

Fig. 1a. Annual average frequency of radical prostatectomy by hospital site in Ontario over the study interval (1993-2006), presented in order of decreasing frequency. The $y$-axis has been truncated for readability. performed at least one of each procedure from this analysis. Statistical analysis was undertaken using SAS 9.2 (SAS Institute, Carey, NC).

This study was supported by the Institute for Clinical Evaluative Sciences (ICES), which is funded by the Ontario Ministry of Health and Long-Term Care (MOHLTC). The opinions, results and conclusions reported in this paper are those of the authors and are independent from the funding sources. No endorsement by ICES or the Ontario MOHLTC is intended or should be inferred. YL and RS had access to the raw data.

\section{Results}

Of the 25346 men who underwent a RP in Ontario during the study interval, $703(2.8 \%)$ underwent subsequent insertion of an AUS and a further $282(1.1 \%)$ underwent a urethral sling procedure (985 total incontinence procedures, $3.9 \%$ ). The median follow-up was 6.8 years, with a mean of 7.4 years (range: 2.0-17.1).

A total of 121 different hospitals in Ontario performed RP over the study period. The distribution of these procedures was highly skewed (Fig. 1a). The median number of annual RPs performed at each site was 3.0 (interquartile range [IQR]: 0.13-17.3) with a mean of 13.49 cases (standard deviation [SD]: 25.75) per year and a maximum and minimum annual average of 200.5 and 0.67 , respectively (Fig. 1a).

A total of 36 hospitals performed AUS or sling insertion, of which 32 also performed RP. Each site performed a median of 0.29 AUS/sling procedures (IQR: 0.083-0.75) and a mean of 1.45 (SD: 3.29) per year with a maximum and minimum annual average of 15.4 and 0.08 , respec-

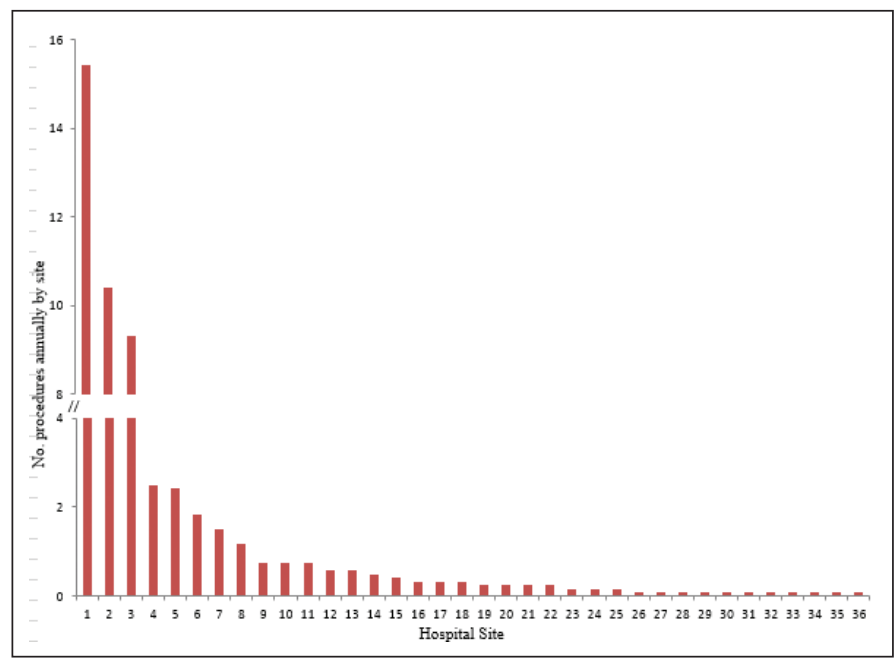

Fig. 1b. Annual average frequency of incontinence procedures (artificial urinary sphincter/sling) by hospital site in Ontario over the study interval (1993-2006), presented in order of decreasing frequency. The $y$-axis has been truncated for readability. 
Wallis et al.

$\begin{aligned} & \text { Table 1. Frequency of incontinence procedure (AUS/ } \\
& \text { sling) and RP being performed at the same site for the } 5 \\
& \text { hospitals performing the greatest number of incontinence } \\
& \text { procedures }\end{aligned}$
\begin{tabular}{ccccc}
\hline Site & $\begin{array}{c}\text { No. AUS/ } \\
\text { slings }\end{array}$ & $\begin{array}{c}\text { AUS/sling and } \\
\text { RP at same site }\end{array}$ & $\begin{array}{c}\text { AUS/Sling and RP } \\
\text { at different sites }\end{array}$ & $\begin{array}{c}\text { Hospital } \\
\text { type }\end{array}$ \\
\hline 1 & 185 & $18(9.7 \%)$ & $167(90.32 \%)$ & Academic \\
2 & 125 & $9(7.2 \%)$ & $114(92.8 \%)$ & Academic \\
3 & 112 & $13(11.6 \%)$ & $99(88 \%)$ & Academic \\
4 & 30 & $2(6.7 \%)$ & $28(93 \%)$ & Academic \\
5 & 29 & $7(24 \%)$ & $22(76 \%)$ & Community \\
\hline \multicolumn{4}{l}{ AUS: artificial urinary sphincter; RP: radical prostatectomy. } & \\
\hline
\end{tabular}

tively (Fig. 1b). For RPs and AUS/sling procedures, the top 3 hospitals performed $21.2 \%$ and $56.2 \%$ of the procedures within the province, respectively. However, the highest volume sites performing RPs were not the same as the highest volume sites performing AUS/sling procedures (Fig. 2).

Most incontinence procedures were performed at a small number of tertiary, university-affiliated institutions, with 3 sites performing $56 \%$ of all incontinence procedures. We found that only $15 \%$ of patients had their AUS or urethral sling procedure at the same hospital where they had their prostatectomy (Table 1). To further examine this practice pattern of managing post-prostatectomy incontinence, we examined the actual versus expected number of incontinence procedures performed at each hospital. We used the baseline rate of $4.8 \%$ to calculate the expected number of $\mathrm{AUS} / \mathrm{sling}$ procedures based on the previous study conducted with the same cohort. ${ }^{4}$ Overall, of the 32 hospitals that performed both RP and AUS/sling procedures, 15 sites performed significantly fewer incontinence procedures than expected, while 5 sites performed significantly more than expected. The remaining 12 sites had insufficient samples sizes to evaluate their observed to expected ratios. When we examined the top 10 centres with the highest annual volume of RPs, 9 performed significantly fewer incontinence procedures than expected from their oncologic case volume ( $p$ range: $<0.0001-0.06$ ) (Table 2 ). Of all 32 hospitals, only

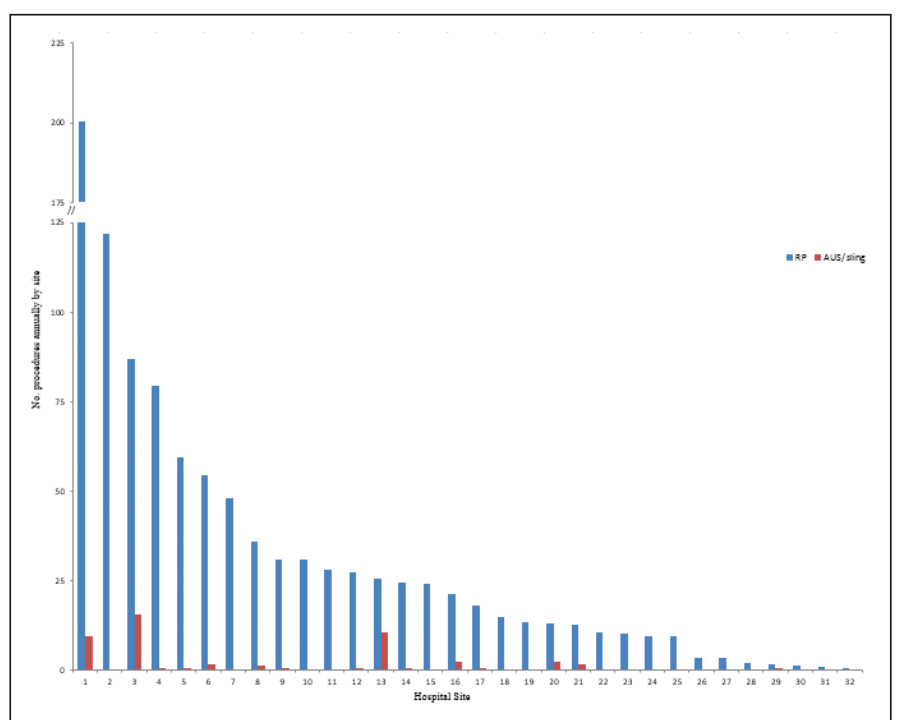

Fig. 2. Annual average frequency of both radical prostatectomy and artificial urinary sphincter/sling procedures by hospital site for those hospitals performing both procedures in Ontario over the study interval (1993-2006), in decreasing frequency of radical prostatectomy. The $y$-axis has been truncated for readability.

site \#3 far exceeded the expected number of AUS/sling procedures based on its RP annual volume (Table 2).

\section{Discussion}

In this study, we characterized the management of post-prostatectomy incontinence in Ontario during 1993 to 2006 from a population-based cohort. We demonstrated that most AUS and sling insertions were performed at a small number of academic sites, and most post-prostatectomy incontinence patients were referred to centres other than where the RP was performed. One academic centre in particular received the bulk of the referrals.

There are many possible reasons for this. The most likely is that the surgeon who performed an RP may not have had expertise in performing an AUS or sling procedure. This is

Table 2. Estimated and actual numbers of incontinence procedures at Ontario hospitals performing both surgeries during the study interval 1993-2006, presented for the 10 highest volume RP sites

\begin{tabular}{|c|c|c|c|c|c|}
\hline Site & $\mathbf{R P}$ & Actual AUS/sling & Expected AUS/sling & Z-score & $p$ value \\
\hline 1 & 3007 & 112 & 144.34 & -2.064 & 0.0390 \\
\hline 2 & 1827 & 1 & 87.70 & -9.320 & $<0.0001$ \\
\hline 3 & 1302 & 185 & 62.50 & 8.185 & $<0.0001$ \\
\hline 4 & 1191 & 9 & 57.17 & -6.010 & $<0.0001$ \\
\hline 5 & 890 & 7 & 42.72 & -5.138 & $<0.0001$ \\
\hline 6 & 815 & 22 & 39.12 & -2.232 & .0256 \\
\hline 7 & 720 & 2 & 34.56 & -5.455 & $<0.0001$ \\
\hline 8 & 536 & 14 & 25.73 & -1.896 & .0579 \\
\hline 9 & 466 & 9 & 22.37 & -2.428 & .0152 \\
\hline 10 & 461 & 4 & 22.13 & -3.598 & .0003 \\
\hline
\end{tabular}


potentiated by the fact that many radical prostatectomies were performed by subspecialized uro-oncologists who were in turn likely to refer their patients requiring incontinence procedures to similarly specialized colleagues in incontinence.

It is also possible that patients may not wish to have the incontinence procedure performed by the same surgeon. However, self-referral urology group practices would provide an opportunity for patients to have their post-prostatectomy incontinence provided by another surgeon within the same hospital or region. Mitchell recently showed that self-referring urology groups in private practice were significantly associated with more referrals for treating prostate cancer with radiation when these groups owned the radiation delivery machines, compared to non-self-referring urology groups. ${ }^{5}$ Since the procedure itself does not require tertiary-level care, there may be other factors responsible for this discrepancy. ${ }^{6-8}$

One of these factors could be the high cost of urinary sphincters and slings to the institution. In Ontario's publicly funded system, these are paid for by the hospital. Patients cannot pay privately for incontinence devices; therefore hospitals are obliged to cover the cost from their annual operating budget if they choose to offer the procedure. Thus, there are cost-saving incentives for both the RP surgeons and hospitals to refer out the management of post-prostatectomy incontinence. This places a financial burden on the institutions providing the bulk of the incontinence surgery. The cost of an AUS varies and is about $\$ 8500 \mathrm{CDN}$ in Ontario. In the United Kingdom, the cost was about $£ 8500^{9}$ in 2010. In the United States, the cost ranged from $\$ 4500$ to $\$ 21700$ between 1998-2000.10,11

We also found that most high volume incontinence centres performed fewer RPs than average. This likely reflects both a small number of surgeons performing incontinence procedures, as well as these surgeons clustering together. We previously showed that patients who undergo RP by high-volume surgeons experience lower rates of AUS/sling procedure. ${ }^{4}$ Thus, patients who undergo AUS/sling surgery by surgeons performing a high volume of post-prostatectomy incontinence procedures will likely also experience better results and lower complication rates.

The established practice pattern of referrals, regardless of etiology, has likely optimized patient care by allowing a few centres (particularly site \#3 in our study) to have high volumes of post-prostatectomy incontinence surgery. As mentioned above, higher volume surgeons are likely to have better outcomes. However, such geographic restriction of these procedures likely negatively affects patients' cancer survivorship due to long wait-times for consultation and surgery, as well as geographic displacement for the surgery.

To our knowledge, no study has examined the referral patterns of AUS use for post-prostatectomy incontinence.
A number of studies have examined overall practice patterns for AUS insertions, regardless of indication. Lee and colleagues found that while AUS usage has increased dramatically since its introduction, only a small proportion of all urologists in the United States (13\%) were performing these procedures for any indication. ${ }^{12}$ Among them, only $4 \%$ performed more than 20 cases per year. Reynolds and colleagues analyzed data from American Medical Systems (AMS), the sole producer of the AUS device, and the American Urological Association. ${ }^{13}$ They found that there was significant geographic variability in the rate of AUS insertions on both the state and regional level, even when corrected for differences in the volume of RP and the distribution of urologists.

Matushita and colleagues further examined all cases submitted to AMS from March 1975 to December 2008 internationally, comprising 86140 cases. $^{14}$ They found significant regional variability both in overall numbers and trends for use; the United States accounted for $62 \%$ of all AUS procedures, with a trend towards increasing rates of use. Other regions, including Canada, France and South America, have experienced a decrease in AUS usage between 2005 and 2008. As with Lee and colleagues, they found that individual surgeon volumes of AUS procedures were very low - this corroborates our findings.

Our study has some limitations. Due to the administrative nature of the data, we could not perform chart reviews to ascertain the specific indications for AUS/sling procedures, to evaluate the extent of patient preoperative incontinence or patient response to surgery. Further, we could not determine the direct patterns of referral from surgeons and sites performing RPs to those performing AUS/sling procedures. Finally, owing to our limited sample size, we were unable to undertake subgroup analysis of the AUS and sling groups separately, owing to a lack of power. While these 2 procedures overlap, they have slightly different indications, outcomes and costs. It would be of interest to examine these differences in an updated cohort in the future.

\section{Conclusion}

Surgical procedures for incontinence following RP are disproportionately performed at a small number of academic sites in Ontario. Given the cost to the institution of the AUS/sling procedures in a publicly funded system, such as Canada, these sites bear an undue financial burden in managing this complication.

Competing interests: Dr. Wallis, Dr. Liu, Dr. Carr, Dr. Kodama, Dr. Klotz and Dr. Nam confirm that they have no relevant financial relationships. Dr. Herschorn has acted as a Consultant and as a principle investigator on scientific studies for Pfizer and Astellas.

This paper has been peer-reviewed. 
Wallis et al.

\section{References}

1. Stanford JL, Feng Z, Hamilton AS, et al. Urinary and sexual function after radical prostatectomy for clinically localized prostate cancer: The Prostate Cancer Outcomes Study. JAMA 2000;283:354-60. http:// dx.doi.org/10.1001/jama.283.3.354

2. Baver RM, Bastian PJ, Gozzi C, et al. Postprostatectomy incontinence: All about diagnosis and manage ment. Eur Urol 2009:55:322-33. http://dx.doi.org/10.1016/i.eururo.2008.10.029

3. Herschorn S, Bruschini H, Comiter C, et al. Surgical treatment of stress incontinence in men. Neurourol Urodyn 2010;29:179-90. http://dx.doi.org/10.1002/nau.20844

4. Nam RK, Herschorn S, Loblaw DA, et al. Population based study of long-term rates of surgery for urinary incontinence after radical prostatectomy for prostate cancer. J Urol 2012;188:502-6. http://dx.doi. org/10.1016/i.juro.2012.04.005

5. Mitchell JM. Urologists' use of intensity-modulated radiation therapy for prostate cancer. N Engl J Med 2013;369:1629-37. http://dx.doi.org/10.1056/NEJMsal201141

6. Wein AJ, Kavoussi LR, Novick AC, et al. Campbell-Walsh Urology, 10th ed. Philadelphia: PA: Elsevier Saunders; 2011.

7. Scott FB. The artificial urinary sphincter: Experience in adults. Urol Clin North Am 1989;16:105-17.

8. Royal College of Physicians and Surgeons of Canada. 2009. Objectives of Training in Urology. http:// www.royalcollege.ca/cs/groups/public/documents/document/y2vk/mdaw/ edisp/tztest3rcpsced000695.pdf.
9. NHS Plymouth Professional Executive Committee: Artificial urinary sphincters for post-prostatectomy incontinence commissioning policy. October 2010. http://www.plymouthpct.nhs.uk. Accessed October 1, 2014.

10. Gomes CM, Broderick GA, Sanchez-Ortiz RF. Artificial urinary sphincter for post-prostatectomy incontinence: impact of prior collagen injection on cost and clinical outcome. J Urol 2000;163:87-90. hittp://dx.doi. org/10.1016/S0022-5347(05)67979-7

11. Brown JA, Elliott DS, Barrett DM. Postprostatectomy urinary incontinence: A comparison of the cost of conservative versus surgical management. Urol 1998;51:715-20. http://dx.doi.org/10.1016/ S0090-4295(98)00123-X

12. Lee $\mathrm{R}$, Te AE, Kaplan $S A$, et al. Temporal trends in adoption of and indications for the artificial urinary sphincter. J Urol 2009;181:2622-7. http://dx.doi.org/10.1016/i.juro.2009.01.113

13. Reynolds WS, Patel R, Msezane L, et al. Current use of artificial urinary sphincters in the United States. J Urol 2007;178:578-83. http://dx.doi.org/10.1016/i.juro.2007.03.146

14. Matushita $\mathrm{K}$, Chughtai BI, Maschino AC, et al. International Variation in artificial urinary sphincter use. Urol 2012;80:667-72. http://dx.doi.org/10.1016/.j.urology.2012.04.065

Correspondence: Dr. Robert K. Nam, 2075 Bayview Ave., Room MG-406, Toronto, ON M4N 3M5; robert.nam@utoronto.ca 